\title{
Clinical Application of Impact Capacitive - Resistive Electric Transfer 448 kHz on Human Cells
}

\author{
Beata Mazurek \\ Department of Clinical Rehabilitation, University of Physical Education, Krakow, Poland \\ Email address: \\ egopowerlab@gmail.com \\ To cite this article: \\ Beata Mazurek. Clinical Application of Impact Capacitive - Resistive Electric Transfer $448 \mathrm{kHz}$ on Human Cells. International Journal of \\ Biomedical Science and Engineering. Vol. 6, No. 3, 2018, pp. 65-69. doi: 10.11648/j.ijbse.20180603.12
}

Received: May 27, 2018; Accepted: November 22, 2018; Published: December 19, 2018

\begin{abstract}
Mesenchymal stem cells (MSCs) can differentiate into more than one type of specialist cells in our body. They are a potential source of progenitor cells for osteoblasts, chondroblasts, adipocytes, skeletal muscles, and cardiomyocytes. They may also differentiate into ecto- and endodermal cell lines, e.g., neural cells, glial cells, hepatocytes and karetinocytes. Mesenchymal cells represent only $0.001-0.01 \%$ of all bone marrow cells, are a crucial population of cells participating in the proliferative phase of damage regeneration, and they are present in nearly all body tissues, the largest number of them is in adipose tissue and blood. Properties of MSCs have formed foundations for a new interdisciplinary field, tissue engineering. Its extensive applications include aesthetic medicine, dermatology, orthopaedics, plastic surgery, physioaesthetics, and sports medicine. The aim of this study is to present selected properties of the mesenchymal stem cells exposed to an electric stimulus of frequency of $448 \mathrm{kHz}$ using Capacitive-Resistive Electric Transfer (CRET) technology.
\end{abstract}

Keywords: Mesenchymal Stem Cells - MSC, Capacitive-Resistive Electric Transfer, Cells Therapy

\section{Introduction}

The subject of interests will be mesenchymal stem cells, being poorly differentiated and having an ability for selfrenewal and proliferation into one or more types of specialised cells concerning observation of changes in their properties and proliferation following exposure to radio-frequency current. Sources for effectively obtaining MSC cells include bone marrow, adipose tissue, umbilical blood, placenta, dental pulp, skeletal muscles and menstrual blood. The research conducted at the scientific and research centre in Spain showed that it is possible to stimulate proliferation of mesenchymal cells using radiofrequency current in a capacitive-resistive electric transfer (CRET) mode. The electrical stimulation gave very satisfactory results in a process of restoring damaged tissues. The best outcome was obtained using the electric current of radio frequency of $448 \mathrm{kHz}$, and this frequency was patented by the research and scientific centre in Barcelona. The developed cell therapy method is called Indiba Activ.

\section{Radio-Frequency Current of $448 \mathrm{KHZ}$ Frequency in CRET Mode}

This technology is based on the current flow through one of two electrodes with an electrical impulse stimulating tissues. The electrode working in the capacitive mode Capasitive - is coated with an insulation layer acting as a dielectric in a capacitor. The metal part of the active electrode is charged positively, while the external layer is made of special plastic material and has a negative charge. Dielectric particles placed in a capacitor electric field become partly or wholly organised (polarisation), and this way an additional electric field, opposite in direction, appears inside of the capacitor. A speed of polarisation changes depends on the wave or the signal frequency. The current reaches patient tissues as a flow of charged ions and particles which collide with immobile particles of the tissue and cause a thermal effect and, what is most important, restore an electrical potential in the cell external environment. The capacitor mode results in a surface effect, improving tissue vascularisation and their anatomic properties. As for a 
resistive electrode, without an insulating layer, that is, without the capacitor dielectric, the electric current is delivered with an ion flow resulting in an increase in the temperature in tissues according to the Joule's law. Heat emitted as a result of current flowing through a tissue is directly proportional to tissue resistance encountered by the current. An energy of the electrical current is transformed into the inner energy of the conductor. In the resistive mode, hyperthermia is located deeper than in the capacitor mode. The flow is possible even in the event of high impedance resulting from a poorer hydration and vascularisation of the tissue. The resistive mode results in restoration of the electric potential inside and outside of the cell following intercellular ion exchange [1].

In a therapy based on the capacitive-resistive electric transfer (CRET), intra- and extracellular stimulation occurs caused by activation of the ion pump; in consequence, the physiological electric function of cells and a normal membrane potential are restored. The intracellular ion exchange is possible due to linear ion movement. Long-term studies of an effect of different frequencies on cells showed that the current frequency has a crucial influence on parameters and a direction of the ion flow. At frequencies below $448 \mathrm{kHz}$, an intracellular effect is not achieved because the membrane behaves as an insulating layer, and only a vibration-like movement of ions is initiated. The 448 $\mathrm{kHz}$ frequency initiates a linear ion flow resulting in intercellular exchange and a cascade of biochemical processes in the cell. Higher frequencies, above $448 \mathrm{kHz}$, cause ions to revolve around their axis resulting in a molecular friction accompanying ion rotation; and this causes only a strong thermal effect without intercellular ion exchange $[2,9]$.

Depending on a dose of the electrical impulse in the capacitive-resistive electric transfer (CRET), one of the three effects can be achieved on a physiological level, i.e., stimulation, vascularisation or hyperactivation. By selecting appropriate current doses while maintaining the $448 \mathrm{kHz}$ frequency, cell metabolism and tissue oxidation can be improved, and tissue microcirculation can increase. Blood vessels are dilated, and efficiency of venous and lymphatic reabsorption improves.

\section{CRET Mode Influence on Mesenchymal Cells Proliferation}

Previous studies on the radio frequency were conducted mainly by research teams in scientific centres: Ramón y Cajal from Madrid, CIMA and QUIRON from Barcelona, Santa Cruz and Sant Pau from Barcelona, University Clinic from Valencia, as well as in Canada, the U.S., UK and Japan. Furthermore, prestigious Institutes of Medicine, Science and Sports CONI from Rome and Gaetano Pini from Milan were involved in the research.

The research showed that exposure of mesenchymal cells to an electrical impulse of $448 \mathrm{kHz}$ used in the CRET cell therapy results in a positive regulation of ERK $1 / 2$ pathway and promotes proliferation of mesenchymal cells obtained from healthy donors. The results indicate effectiveness of the CRET therapy in repair processes in an injured area by active proliferation of cells obtained from adipose tissues. The adipose tissue is the best source of stem cells in adult people [2].

An exposure to pulsed electrical impulse of $448 \mathrm{kHz}$ used in therapies with the capacitive-resistive electric transfer increases a percentage of cells in S, G2 and mitosis phases, as well as causes proliferation of mesenchymal stem cells in humans. The obtained results show that the CRET electrical treatment may stimulate tissue regeneration through activation of proliferation of resting adipose derived stem cells (ADSC) present in the damaged area, without compromising multipotential nature of stem cells in terms of future adipogenic, chondrogenic, or osteogenic differentiation. This data, together with previously published experimental evidence, strongly supports the hypothesis that molecular and cellular mechanisms, other than thermal ones, may be of crucial importance for the therapeutic effectiveness of treatment with the CRET method. Therefore, CRET can be proposed as an effective auxiliary method in regeneration of various lesions in tissues and vessels [3].

In vitro differentiation of mesenchymal stem cells in a specific direction requires the use of specific growth factors or chemical compounds having differentiation properties. Selected factors determining MSC differentiation are presented in the table below [4].

Table 1. Selected Factors Regulating Msc Differentiation.

\begin{tabular}{ll}
\hline Biological and chemical differentiating factors & Differentiation directions \\
\hline TGF- $\beta$ & chondrocytes, smooth myocytes \\
IGF-1 & chondrocytes \\
bFGF & chondrocytes, osteoblasts, neurons \\
EGF & chondrocytes \\
PDGF & chondrocytes, myofibroblasts, smooth myocytes \\
VEGF & endothelial cells \\
BMP-12 & cenocytes \\
Dexametasone + isobutylmethylxanthine + indomethacin+insulin & adipocites \\
Ascorbic acid & chondrocytes \\
$\beta$-glycerophosphate & osteoblasts \\
5 '-azacitidine & cardiomyocytes \\
Linoleic acid & oligodendrocytes, neurons \\
DMSO + dexametasone & astrocytes \\
\hline
\end{tabular}




\section{MSC Proliferation into Chondrocytes and Osteoblasts Stimulated by an Electrical Impulse in CRET Mode}

Growth factors modulating differentiation of mesenchymal stem cells include a family of TGF-b (TGF-b1, TGF-b2 and TGF-b3) factors, as well as bone morphogenetic proteins (BMPs). In studies on human MSC it was found that TGF-b2 and TGF-b3 are more active than TGF-b1. Following TGFb2 and TGF-b3 stimulation, the synthesis of proteoglycans and type II collagen increased. Bone morphogenetic proteins (BMPs) $[2,4,6]$ participate in MSC differentiation towards cartilage cells [26]. Cartilage regeneration is a difficult process due to high resistance, low proliferation index and poor vascularisation of this tissue. Studies on the influence of the electrical impulse in the CRET mode on damaged cartilage showed that the induction effect of stem cell proliferation supports cartilage regeneration by an increase in differentiation of stem cells towards cartilage cells, synthesis of chondrocytes in tissues and of macrocytes $\mathrm{C}$ in extracellular matrix of the cartilage. A stimulation in the resistive mode increases proliferation and accelerates mesenchymal cells differentiation into chondrocytes and osteoblasts, thus accelerating the process of healing of injured tendons and cartilages, and shortening the time required for bone union. [5, 6]

Experimental results provided evidence that stimulation with radio-frequency current in the CRET mode acts at a cellular level. Stem cells exhibit an increased expression and activation of Sox-5, molecules involved in chondrogenesis and formation of cartilage. The studies revealed an accelerated synthesis of the cartilage matrix in a presence of chondroitin sulphate and glycosaminoglycans (KNEBEL). Beneficial therapeutic effects were also demonstrated in patients with damaged bone tissue, and with degenerative lesions undergoing CRET-based treatment. The studies showed that apart from differentiation of stem cells into osteoblasts (bone cells), an activity of alkaline phosphatase also increases, calcium deposits are formed and mineralisation and formation of bone tissue accelerates [2].

Figure 1 shows an effect of the electrical impulse in the CRET mode on proliferation of cells isolated from the adipose tissue. The photos show an effect after 14 days of the exposure to the electrical impulse. Visible differentiation into different types of cells: adipocytes, chondrocytes and osteocytes [8].
Adipocytes
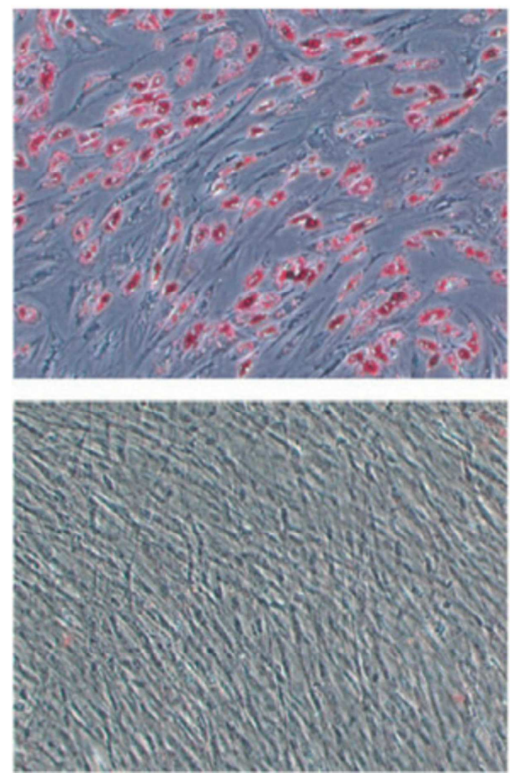

Chondrocytes
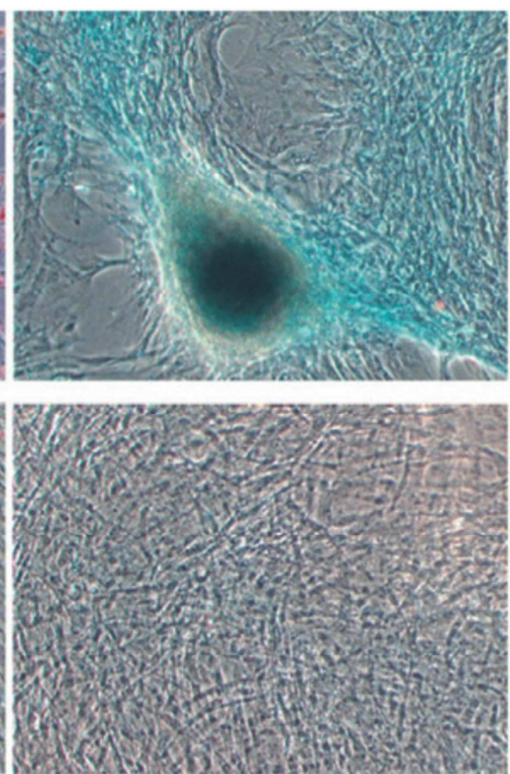

Figure 1. Different types of human cells.

\section{Osteocytes}
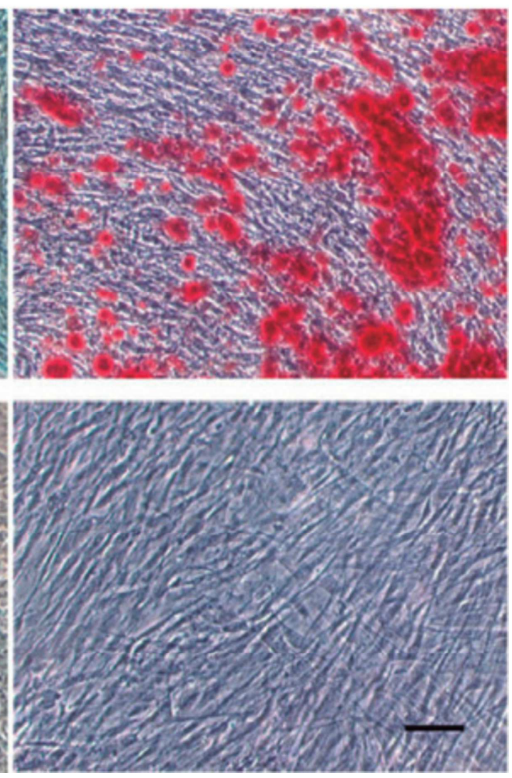

\section{CRET Therapy in Sports}

Due to the therapeutic effects at a cellular level described above, electrotherapy in the CRET mode is used in sports orthopaedics and rehabilitation. It is used by over 200 sports federations all over the world. CRET electrotherapy is used, amongst the others, by: FC Barcelona, Espanyol, AC Roma, and Tinkoff SAXO. In Poland, the CRET cell therapy was used by physiotherapists of the National Football team during their preparations to EURO 2016 and supported players of the National Handball Team at the Olympic Games in Rio. At the Ego Power Lab, the CRET technology based on the $448 \mathrm{kHz}$ frequency is used by Polish Women Basketball Champions from Wisła Can-Pack team and many champions and Olympic athletes from various disciplines, including kayakers, football players, race walkers, runners, judokas, cyclists, MMA wrestlers, Rugby and American football players. The CRET technology is used to treat sports and orthopaedic injuries, as well as for post-exercise regeneration 
and to prepare muscles for the exercise. Currently, the first in Poland study will be conducted at the University of Physical Education in Krakow, concerning the effect of the electrotherapy in the capacitive-resistive mode at the 448 $\mathrm{kHz}$ frequency on rheological, biochemical, hormonal and enzymatic properties of blood in terms of post-exercise regeneration and prevention of myocardial infarctions and embolism in runners above 40 years of age. The Ego Power Lab Foundation, carrying out scientific projects, has developed a proprietary, comprehensive program for the prevention of sports injuries: preparation of muscles for effort, acceleration of anabolism after exercise.

\section{Conclusion}

Capacitive-Resistive Electric Transfer (CRET) technology is found to be the new therapeutic method in a treatment of many morbidities such as injuries, inflammation or just in regeneration of body tissues. The main principle of it's therapeutic side is stimulation and increase in intra- and extracellular ion substitution by recovery of the physiological bioelectrical activity of cells. Therapy in CRET mode on frequency $448 \mathrm{kHz}$ stimulate mesynchemal stem cells to faster mature and profileration resulting in quicker regeneration processes in damaged tissues.

\section{References}

[1] Schaffler A, Buchler C: Concise review: Adipose tissuederived stromal cells--basic and clinical implications for novel cell-based therapies. Stem Cells 2007; 25:818-827.

[2] Hernández-Bule ML, Paíno CL, Trillo MÁ and Úbeda A: Electric stimulation at $448 \mathrm{kHz}$ promotes proliferation of human mesenchymal stem cells. Cell Physiol Biochem. 34:1741-1755. Published online 2016 Mar 21. doi: 10.3892/mmr.2016.5032.

http//www.ncbi.nlm.nih.gov/pmc/articles/PMC4838151.

[3] S. Karger. Electric stimulation at $448 \mathrm{kHz}$ promotes proliferation of human mesenchymal stem cells. Departamento de Investigación-BEM, Hospital Universitario Ramón y Cajal - IRYCIS, Madrid, Spain. (http://www.ncbi.nlm.nih.gov/pubmed/25427571).

[4] Shah, S. G. S. and Farrow, A. (2012) Trends in the Availability and Usage of Electrophysical Agents in Physiotherapy Practices from 1990 to 2010: A Review. Physical Therapy Reviews, 17 (4): 207- 226. Published online 2016 Mar http://dx.doi.org/10.1179/1743288x12y.0000000007.

[5] Watson T. Electrotherapy: Evidence Based Practice. 12th ed. London: Elsevier Churchill Livingstone; 2008; 45-48.

[6] Bajek A, Olkowska J, Gurtowska N, Kloskowski T, Walentowicz-Sadlecka M, Sadlecki P, Grabiec M, Drewa T. Human amniotic-fluid-derived stem cells: a unique source for regenerative medicine. Expert Opin Biol Ther. 2014 Jun; 14 (6):831-9. doi: 10.1517/14712598.2014.898749. Review. PMID: 24655038.

[7] Binoy Kumaran. Apacitive Resistive Monopolar
Radiofrequency (CRMRF) therapy at $448 \mathrm{KHz}$ : the effects on deep blood flow and elasticity of tissues. 2016 Jun 21. https://www.researchgate.net/publication/283078888_Capaciti ve_Resistive_Monopolar_Radiofrequency_CRMRF_therapy_ at_448_KHz_the_effects_on_deep_blood_flow_and_elasticity of tissues.

[8] Chamberlain G., Fox J., Ashton B., Middleton J.: Concise review: mesenchymal stem cells: their phenotype, differentiation capacity, immunological features, and potential for homing. Stem Cells, 2007; 25: 2739-2749.

[9] Jackson L., Jones D. R., Scotting P., Sottile V.: Adult mesenchymal stem cells: differentiation potential and therapeutic applications. J. Postgrad. Med., 2007; 53: 121127.

[10] María Luisa HernándezBule, Javier MartínezBotas, María Ángeles Trillo, Carlos L Paíno, Alejandro Úbeda. Antiadipogenic effects of subthermal electric stimulation at $448 \mathrm{kHz}$ on differentiating human mesenchymal stem cells. Published online on: Monday, March 21, 2017 Pages: 38953903 DOI: $10.3892 / \mathrm{mmr} .2016 .5032$ (https://www.spandidospublications.com/mmr/13/5/3895/abstract).

[11] Belenky I, Margulis A, Elman M, Bar-Yosef U and Paun SD: Exploring channeling optimized radiofrequency energy: A review of radiofrequency history and applications in esthetic fields. Adv Ther. 29:249-266. 2012. View Article: Google Scholar: PubMed/NCBI.

[12] Hamida ZH, Comtois AS, Portmann M, Boucher JP and Savard R: Effect of electrical stimulation on lipolysis of human white adipocytes. Appl Physiol Nutr Metab. 36:271275. 2011. View Article: Google Scholar: PubMed/NCBI.

[13] Kato S, Saitoh Y and Miwa N: Repressive effects of a capacitive-resistive electric transfer (CRet) hyperthermic apparatus combined with provitamin $\mathrm{C}$ on intracellular lipiddroplets formation in adipocytes. Int J Hyperthermia. 29:30 37. 2013. View Article: Google Scholar: PubMed/NCBI.

[14] Hernández-Bule ML, Roldán E, Matilla J, Trillo MA and Ubeda A: Radiofrequency currents exert cytotoxic effects in NB69 human neuroblastoma cells but not in peripheral blood mononuclear cells. Int J Oncol. 41:1251-1259. 2012. PubMed/NCBI.

[15] Messerli MA, Graham DM: Extracellular electrical fi elds direct wound healing and regeneration. Biol Bull 2011; 221:79-92.

[16] Pilla AA: Nonthermal electromagnetic fi elds: From fi rst messenger to therapeutic applications. Electromagn Biol Med 2013; 32:123-136.

[17] Belenky I, Margulis A, Elman M, Bar-Yosef U, Paun SD: Exploring channeling optimized radiofrequency energy: A review of radiofrequency history and applications in esthetic fi elds. Adv Ther 2012; 29:249-266.

[18] Boyette MY, Herrera-Soto JA: Treatment of delayed and nonunited fractures and osteotomies with pulsed electromagnetic fi eld in children and adolescents. Orthopedics 2012; 35:e1051-1055.

[19] Whipple TL: From mini-invasive to non-invasive treatment using monopolar radiofrequency: The next orthopaedic frontier. Orthop Clin North Am 2009; 40:531-535, x. 
[20] Ganzit GP, Stefanini L, Stesina G: Nuove methodice nei trattamento della patología muscolo-articolare dell'atleta: $\mathrm{La}$ tercaterapia. Med Sport 2000; 53:361-367.

[21] Ley Valle A.: Tratamiento quirúrgico de los gliomas malignos. In: Ley Valle Tumores del sistema nervioso central, Barcelona: Doyma, 1993, 55-64.

[22] Martínez R. A., Bordás J. R.: Tratamiento del asma mediante transferencia eléctrica capacitiva, Rehabilitación Física, XXI 1992, 3: 18-19.

[23] Hernandez-Bule M. L., Cid M. A., Trillo M. A. i wsp.: Cytostatic response of HepG2 to $0.57 \mathrm{MHz}$ electric currents mediated by changes in cell cycle control proteins. „International Journal of Oncology”, 37: 1399-1405, 2010.

[24] Hernandez-Bule M. L., Ubeda A.: In vitro Cytostatic Response to 0.57- MHz Electric Currents, Department of Bioelectromagnetismo-Investigacion, Hospital Ramon y Cajal, Madrid, Spain 2009.

[25] Filip S., Mokry J., Horacek J., English D.: Stem cells and the phenomena of plasticity and diversity: a limiting property of carcinogenesis. Stem Cells Dev., 2008; 17: 1031-1038.
[26] Burke Z. D., Tosh D.: Therapeutic potential of transdifferentiated cells. Clin. Sci., 2005; 108: 309-321.

[27] Shen C. N., Burke Z. D., Tosh D.: Transdifferentiation, metaplasia and tissue regeneration. Organogenesis, 2004; 1 : $36-44$.

[28] Qi L, Shen H, Larson I, Schaefer EJ, Greenberg AS, Tregouet DA, Corella D, Ordovas JM (November 2004). "Genderspecific association of a perilipin gene haplotype with obesity risk in a white population". Obes. Res. 12 (11): 1758-65. doi:10.1038/oby.2004.218. PMID 15601970.

[29] Corella D, Qi L, Sorlí JV, Godoy D, Portolés O, Coltell O, Greenberg AS, Ordovas JM (September 2005). "Obese subjects carrying the $11482 \mathrm{G}>\mathrm{A}$ polymorphism at the perilipin locus are resistant to weight loss after dietary energy restriction". J. Clin. Endocrinol. Metab. 90 (9): 5121-6. doi:10.1210/jc.2005-0576. PMID 15985482. 